\title{
Release of alpha emitters into the environment by nuclear industries of Brazil in Resende
}

\author{
W. S. Pereira ${ }^{\mathrm{a}, \mathrm{b}}$; A. Kelecom ${ }^{\mathrm{c}}$, R. Santos ${ }^{\mathrm{a}}$; M. F. M. Santos ${ }^{\mathrm{a}}$; V. R. M. Torres ${ }^{\mathrm{a}}$, \\ J. J. S. Rodrigues ${ }^{\mathrm{a}}$, C. M. Salgado ${ }^{\mathrm{d}}$ and I. C. R. P. Valadão ${ }^{\mathrm{b}}$ \\ ${ }^{a}$ Fábrica de Combustível Nuclear, Indústrias Nucleares do Brasil - FCN/INB, 27555-000, Resende, RJ, Brasil \\ pereiraws@gmail.com \\ ${ }^{b}$ Universidade Veiga de Almeida, 20271-020, Rio de Janeiro, RJ, Brasil \\ ${ }^{c}$ Universidade Federal Fluminense, 24021-141, Niterói, RJ, Brasil \\ ${ }^{d}$ Divisão de Radiofármacos/Instituto de Engenharia Nuclear, 21941-906, Rio de Janeiro, RJ, Brasil \\ otero@ien.gov.br
}

\begin{abstract}
During its operation, the Nuclear Fuel Factory of the Nuclear Industries of Brazil (FCN/INB) may generate and disseminate particulate material. Therefor, aiming occupational control, a system of air exhaustion is installed equipped with a system of automatic detection of release of radionuclides into the environment. The present work aims to evaluate the radionuclides released by FCN, in terms of total release and activity concentration (AC). Along 2016, the amount of $4.14 \cdot 10^{6} \mathrm{~Bq}$ was released, which means a mean of $3.45 \cdot 10^{5} \mathrm{~Bq} \cdot$ month $^{-1}$. The largest mean for AC was 4.03 $\mathrm{mBq} \cdot \mathrm{m}^{-3}$. The release data was almost an order of magnitude lower than the annual release limit established by the regulatory agency, fixed at $1.2 \cdot 10^{7} \mathrm{~Bq} \cdot \mathrm{y}^{-1}$, proving the adequacy of the atmospheric effluents to the licensing requirements. The largest magnitudes of the two variables (AC and release) were observed in August while the smallest ones, in January.
\end{abstract}

Keywords: alpha emitters, nuclear fuel factory, atmospheric effluents 


\section{INTRODUCTION}

Nuclear installations can cause environmental radiological impact. Once they expose the workers and the surrounding population to radiation, they are considered practices and, therefore, regulated by the National Commission for Nuclear Energy (Comissão Nacional de Energia Nuclear - CNEN, in Portuguese). These practices are given by international organizations such as the International Atomic Energy Agency (IAEA) (IAEA, 2014a) and are followed by the Brazilian legislation, supervised by CNEN (CNEN, 2014a).

The IAEA establishes standards of environmental monitoring practices, which include generic environmental impact assessment models (IAEA, 2011a), monitoring standards (IAEA, 2005), public involvement in decision-making (IAEA, 2006), physical security (IAEA, 2014b; IAEA, 2016a), choice (IAEA, 2015) and assessment of sites for nuclear installation (IAEA, 2016b), beyond hydrological and meteorological standards (IAEA, 2011b), and standards to the monitoring of the facilities responsible for the storage of radioactive waste generated in practice (IAEA, 2014c). These international standards serve as a basis for CNEN's national radiation protection legislation (CNEN, 2014a), nuclear licensing (CNEN, 2002), radiological environmental impact assessment and monitoring (CNEN, 2011), transport of radioactive material (CNEN, 1988), and management of radioactive waste (CNEN, 2014b), etc.

The Nuclear Fuel factory (Fábrica do Combustível Nuclear - FCN, in Portuguese) in Resende, RJ is responsible for four steps of the Nuclear Fuel Cycle: uranium enrichment, $\mathrm{UF}_{6}$ to $\mathrm{UO}_{2}$ conversion, production of pellets, and fabrication of the fuel assemblies intended for energy generation in reactors of nuclear power plants. A fifth step, the conversion process, is being planned and is presently in technical and economic evaluation phase for its implementation.

In the pellet fabrication unit of Nuclear Fuel factory (FCN-II), open sources are manipulated when the enriched uranium, in powder form, passes through physical processes like compaction and sintering for its transformation into pellets. These procedures can lead to an atmosphere contamination condition inside of the facility. Thus, as part of the occupational safety, the plant has been designed to prevent the spreading of the dust to the outside of the facility. Beyond the containment there is an air exhausting system, which renews the factory atmosphere six times per 
hour. It is composed by an air filtration system that ensures that the facility does not exceed the release limit of alpha emitters into the air, which is currently fixed by the regulatory agent at $1.2 \cdot 10^{7}$ Bq. $\mathrm{y}^{-1}$. The present work aims to evaluate the release of alpha emitting radionuclides and the activity concentration (AC) released into the atmosphere by FCN during 2016.

\section{MATERIALS AND METHODS}

The system of exhaustion of the FCN-II possesses an air sampling system for the detection of alpha emitting particles present in the air. The equipment, from Thermo Scientific, is endowed of a radiation detector based on "Alpha Energy Range Discrimination" (AERD) system, and the counting method employs primary and secondary proportional counter tubes separated by a foil and an electronic evaluation system to optimize the detection of alpha emitters in the air.

The system collects samples of air from the chimney and counts in real time the AC of alpha emitters. Associated with it there is another system responsible for measuring the sampled airflow and, together, they allow the evaluation of the activity concentration, in $\mathrm{mBq} \cdot \mathrm{m}^{-3}$, and the total release of alpha emitting radionuclides, in $\mathrm{Bq}$.

The AC values were tabulated and organized in monthly means, as well as the records of maximum and minimum values detected at the source. Using the airflow values, the emission values of alpha emitting radionuclides $(\mathrm{Bq})$ were calculated, and then organized by monthly and annual release values. A statistical analysis of mean alpha emitters AC and monthly releases was performed aiming to obtain the temporal variations of the two variables, through analysis of variance (ANOVA) (ROSNER, 2000). The Tukey test was used to complement the evaluation, grouping the means by their magnitudes (SCHORK and REMINGTON, 2000; FERREIRA, 2008).

\section{RESULTS AND DISCUSSION}

The values of the descriptive statistics on data of the alpha emitter radionuclides released in to the air from the (FCN-II) are shown in Table 1 and Figure 1. The means of release values and the cumulative release variation during 2016 can be seen in Table 2 and Figure 2, respectively. 
Table 1: Descriptive statistic of release of alpha-emitting radionuclides by FCN-II, during 2016.

\begin{tabular}{lcccc}
\hline Month & Minimum $\left(\mathbf{B q} \cdot \mathbf{m}^{-3}\right)$ & Mean $\left(\mathbf{B q} \cdot \mathbf{m}^{-3}\right)$ & Maximum $\left(\mathbf{B q} \cdot \mathbf{m}^{-3}\right)$ & Release $(\mathbf{B q})$ \\
\hline Jan & $2.00 \cdot 10^{-4}$ & $1.88 \cdot 10^{-3}$ & $1.10 \cdot 10^{-2}$ & $2.25 \cdot 10^{5}$ \\
\hline Feb & $6.00 \cdot 10^{-4}$ & $4.00 \cdot 10^{-3}$ & $2.83 \cdot 10^{-2}$ & $3.54 \cdot 10^{5}$ \\
\hline Mar & $4.00 \cdot 10^{-4}$ & $2.38 \cdot 10^{-3}$ & $6.90 \cdot 10^{-3}$ & $2.83 \cdot 10^{5}$ \\
\hline Apr & $2.00 \cdot 10^{-4}$ & $3.63 \cdot 10^{-3}$ & $1.01 \cdot 10^{-2}$ & $4.55 \cdot 10^{5}$ \\
\hline May & $2.00 \cdot 10^{-4}$ & $2.22 \cdot 10^{-3}$ & $7.40 \cdot 10^{-3}$ & $2.86 \cdot 10^{5}$ \\
\hline Jun & $2.00 \cdot 10^{-4}$ & $2.21 \cdot 10^{-3}$ & $6.30 \cdot 10^{-3}$ & $2.76 \cdot 10^{5}$ \\
\hline Jul & $3.00 \cdot 10^{-4}$ & $3.81 \cdot 10^{-3}$ & $1.19 \cdot 10^{-2}$ & $4.71 \cdot 10^{5}$ \\
\hline Aug & $1.54 \cdot 10^{-6}$ & $4.03 \cdot 10^{-3}$ & $2.46 \cdot 10^{-2}$ & $5.68 \cdot 10^{5}$ \\
\hline Sep & $4.00 \cdot 10^{-4}$ & $2.66 \cdot 10^{-3}$ & $9.10 \cdot 10^{-3}$ & $2.93 \cdot 10^{5}$ \\
\hline Oct & $1.40 \cdot 10^{-6}$ & $2.26 \cdot 10^{-3}$ & $1.33 \cdot 10^{-2}$ & $2.70 \cdot 10^{5}$ \\
\hline Nov & $2.00 \cdot 10^{-4}$ & $2.40 \cdot 10^{-3}$ & $7.60 \cdot 10^{-3}$ & $2.75 \cdot 10^{5}$ \\
\hline Dec & $5.00 \cdot 10^{-4}$ & $3.31 \cdot 10^{-3}$ & $1.60 \cdot 10^{-2}$ & $3.85 \cdot 10^{5}$ \\
\hline
\end{tabular}

Figure 1: Temporal variation of mean, minimum and maximum of activity concentration release of alpha emitters by $F C N-I I$, in $\mathrm{mBq} \cdot \mathrm{m}^{-3}$, in 2016

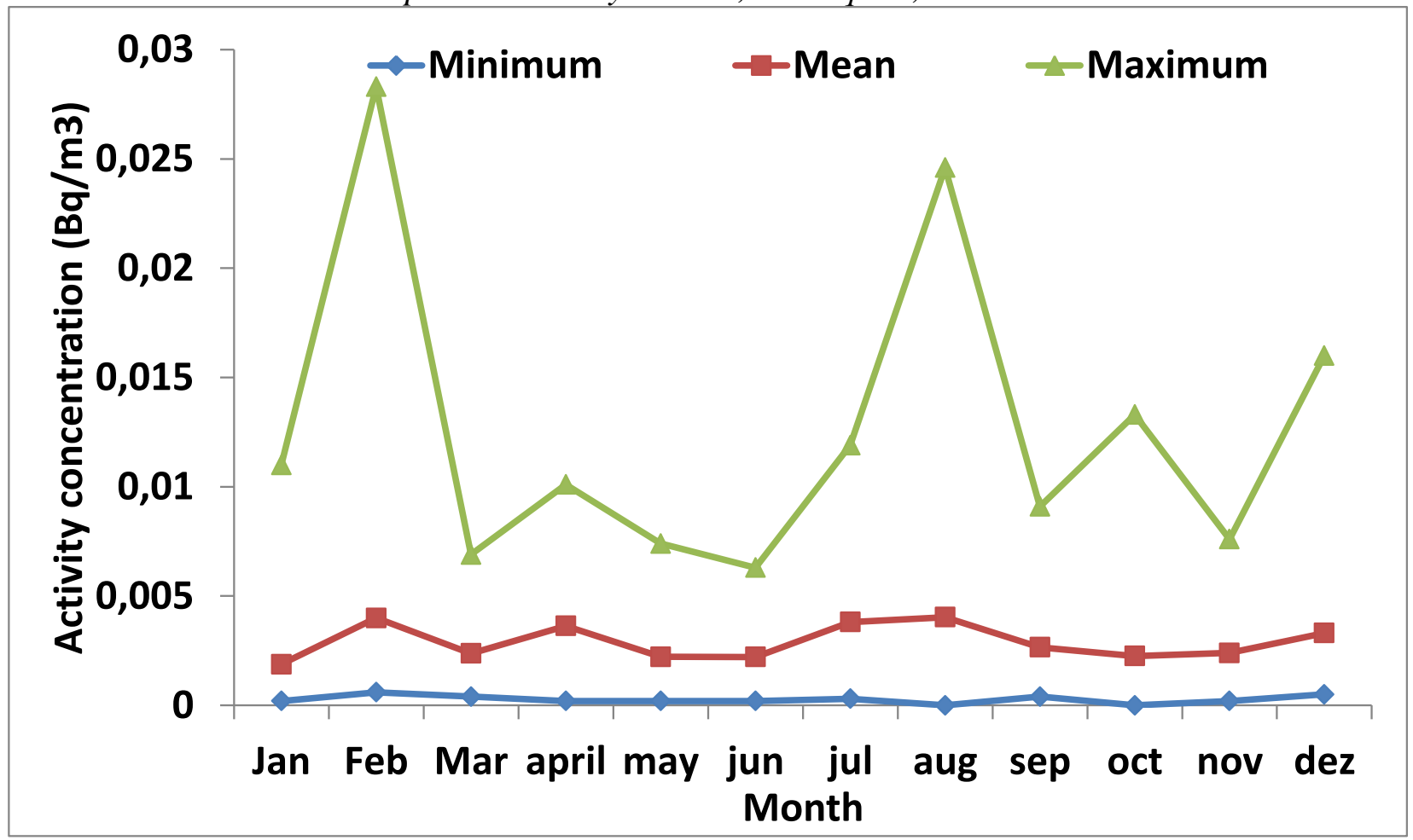


Table 2: Monthly release, cumulative release and annual release limit of alpha-emitting radionuclides during 2016, in $\mathrm{MBq}$.

\begin{tabular}{lcccccccccccc} 
Month & Jan & Feb & Mar & Apr & May & Jun & Jul & Aug & Sep & Oct & Nov & Dec \\
\hline $\begin{array}{l}\text { Monthly } \\
\text { release }\end{array}$ & 0.23 & 0.35 & 0.28 & 0.46 & 0.29 & 0.28 & 0.47 & 0.57 & 0.29 & 0.27 & 0.28 & 0.39 \\
\hline $\begin{array}{l}\text { Cumulative } \\
\text { release }\end{array}$ & 0.23 & 0.58 & 0.86 & 1.32 & 1.60 & 1.88 & 2.35 & 2.92 & 3.21 & 3.48 & 3.76 & 4.14 \\
\hline $\begin{array}{l}\text { Annual release } \\
\text { limit }\end{array}$ & & 0 & \multicolumn{1}{c}{12.00} \\
\hline
\end{tabular}

The authorized release limit generates in the facility critical group the annual dose limit established in Brazilian legislation $\left(1.2 \cdot 10^{7} \mathrm{~Bq} \cdot \mathrm{y}^{-1}\right.$, equal to $\left.0.3 \mathrm{mSv} \cdot \mathrm{y}^{-1}\right)$. Since there is a directly proportional relationship between release and dose it is possible to estimate the monthly doses, as can be seen in Table 3. The estimated annual dose was approximately one third of the value established in the standard (CNEN, 2014a).

In addition to the annual release of alpha radionuclides emitted by the facility, the concentration of activity, in $\mathrm{mBq} \cdot \mathrm{m}^{-3}$, is a key variable in environmental radioprotection, since it allows estimating the term source and its variation.

Figure 2: Monthly release, cumulative release and annual release limit of alpha-emitting radionuclides in FCN-II during 2016, in $\lg _{10} \mathrm{~Bq}$

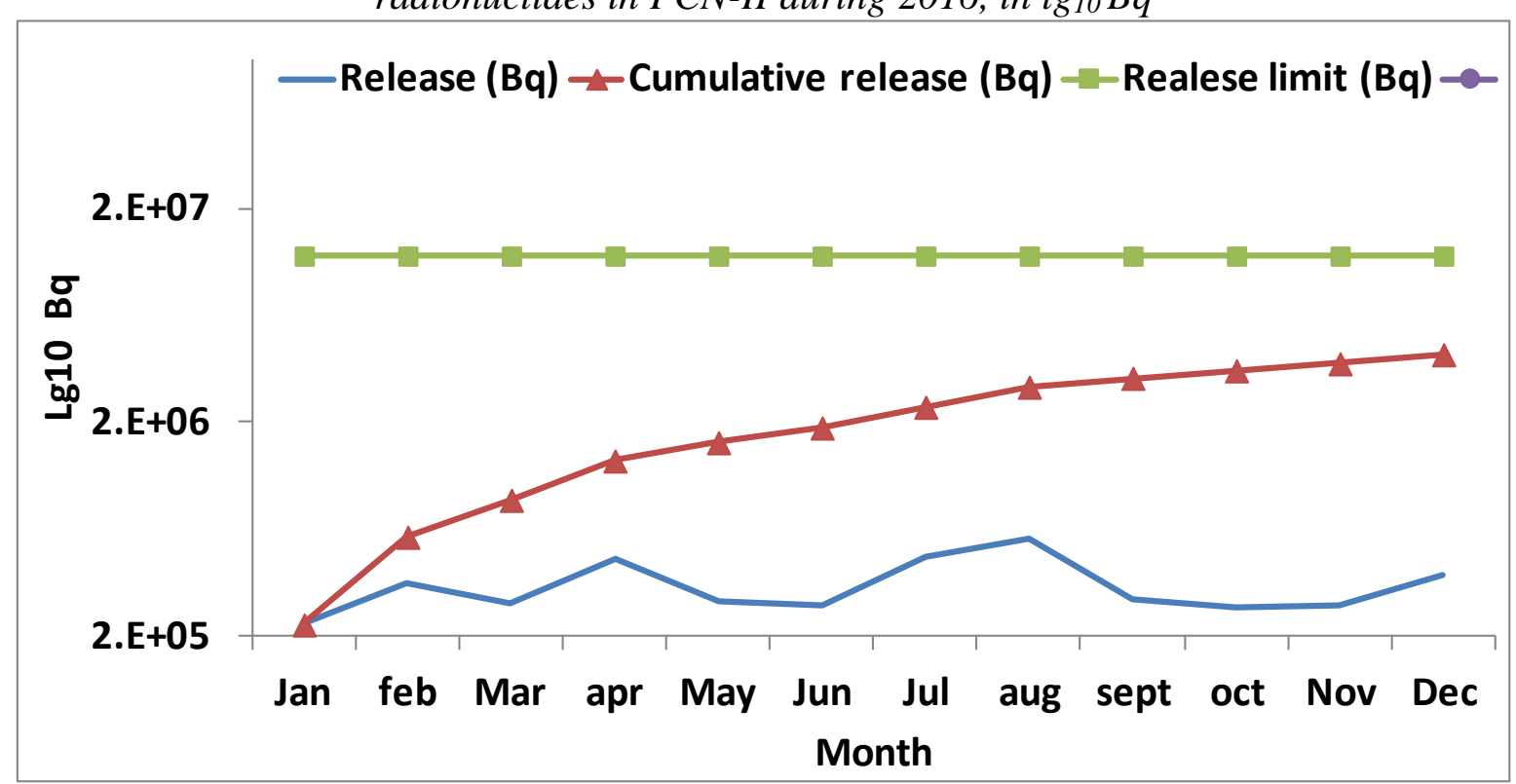





defined by the regulatory authority, which is $12 \mathrm{MBq}^{-1}$. The total release for 2016 was 4.14 $\mathrm{MBq} \cdot \mathrm{y}^{-1}$, which corresponds to less than half of the allowed release value. The accumulated release in the months showed a linear trend, as can be seen in Figure 3.

Figure 3: Variation of the release of cumulative release demonstrating the linear relationship between the cumulative release and the time

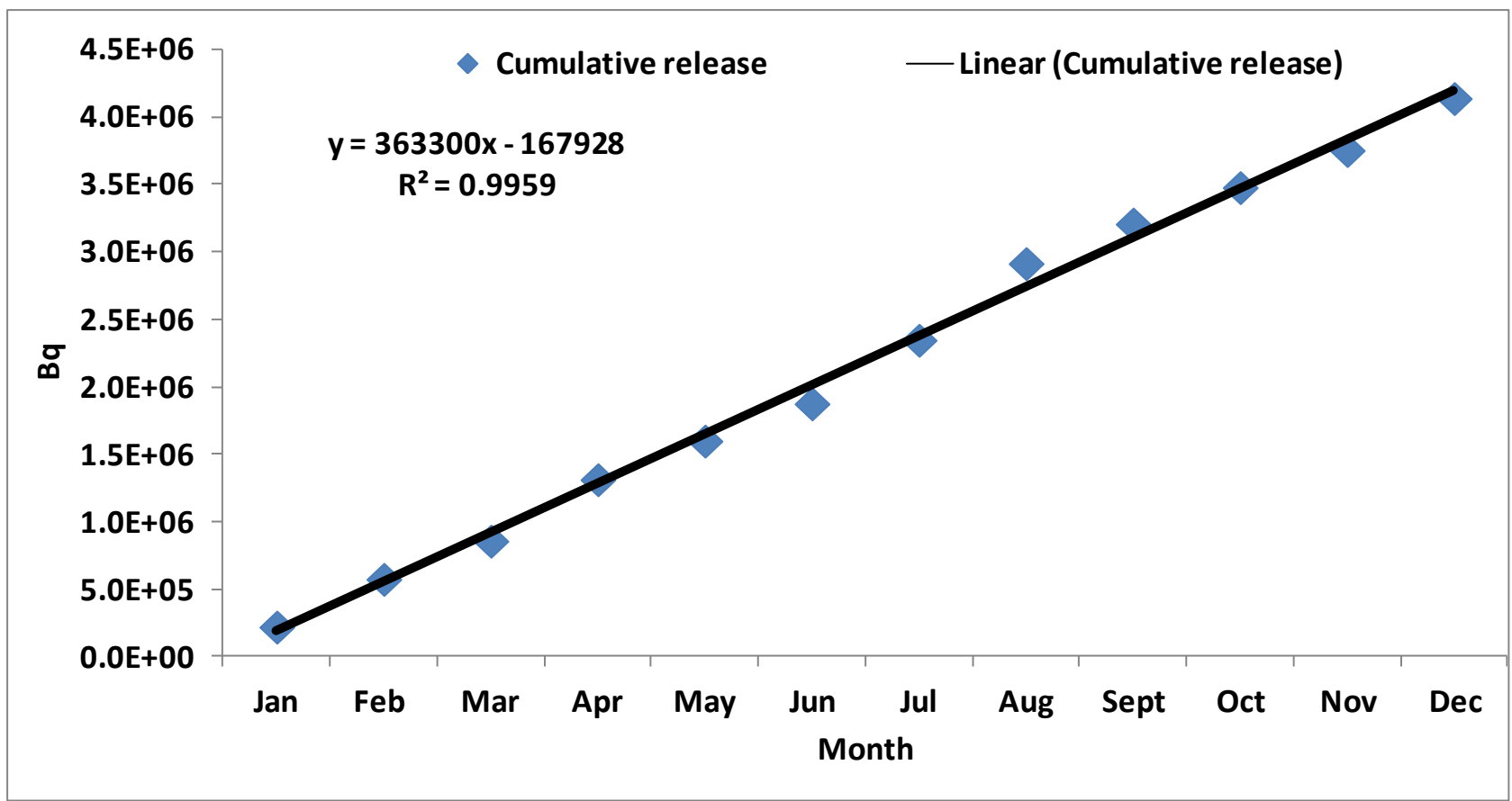

Table 3: Average monthly dose, cumulative dose and annual dose limit in the critical group due to the release of alpha emitters by the FCN-II, in $\mu$ Sv.

\begin{tabular}{lcccccccccccc}
\hline Month & Jan & Feb & Mar & Apr & May & Jun & Jul & Aug & Sep & Oct & Nov & Dec \\
\hline Monthly dose & 6 & 9 & 7 & 11 & 7 & 7 & 12 & 14 & 7 & 7 & 7 & 10 \\
\hline Cumulative dose & 6 & 14 & 22 & 33 & 40 & 47 & 59 & 73 & 80 & 87 & 94 & 104 \\
\hline Dose limit & & & \multicolumn{8}{c}{300} \\
\hline
\end{tabular}

Evaluating the two variables studied, total release (MBq.month ${ }^{-1}$ ) and Activity concentration (in $\left.\mathrm{mBq} \cdot \mathrm{m}^{-3}\right)$, a high correlation is verified $\left(\mathrm{R}^{2}=0.84\right)$, which can be seen in Figure 4 . 
Figure 4: Time variation of the averages of accumulated release and activity concentration

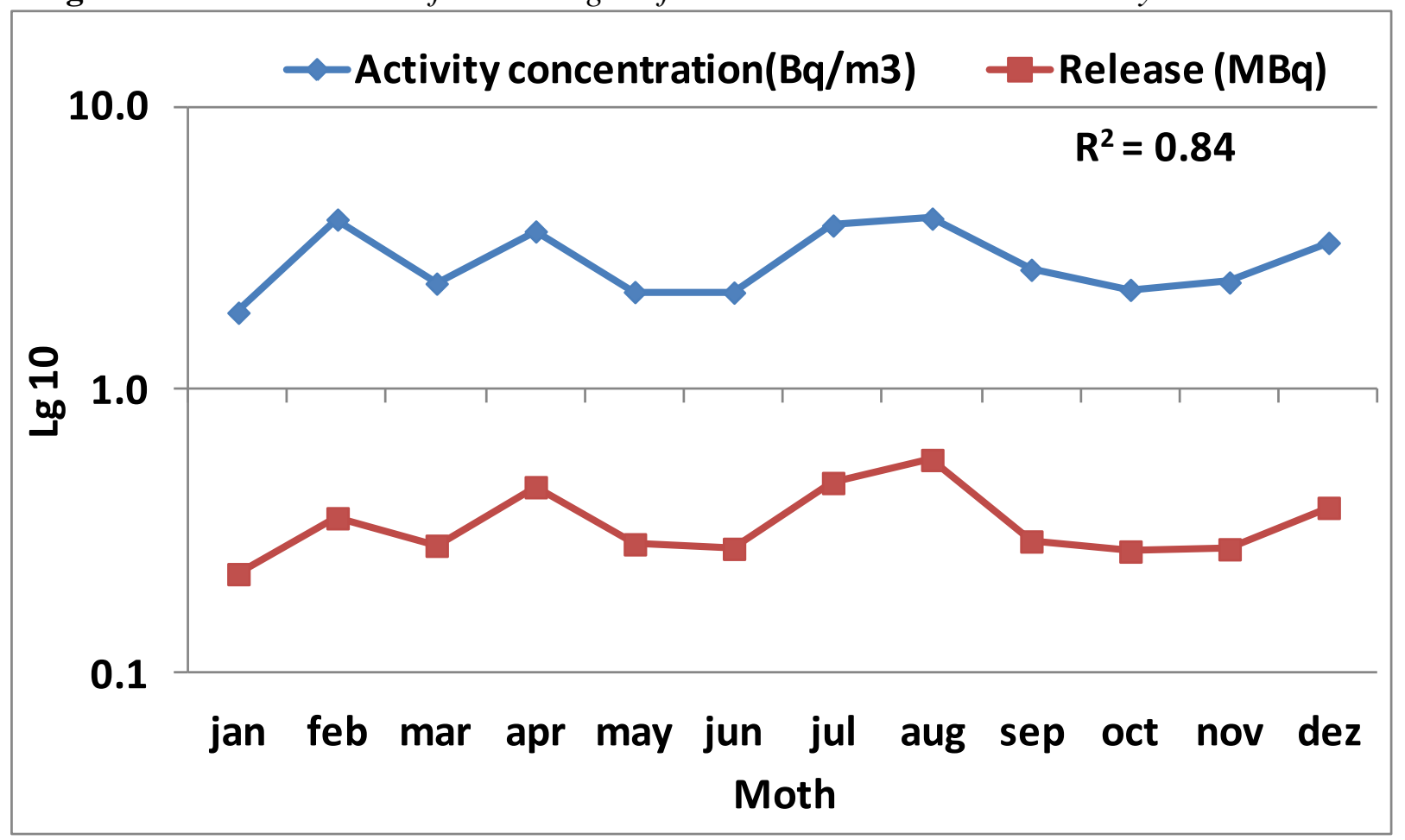

Even with a high correlation when using the statistical analysis of the ANOVA test, followed by the Tukey test, for grouping the means, a slightly different behavior between the variables is verified. Evaluating the magnitudes of the means of the total release (in $\mathrm{MBq}$ ), with the ANOVA, a variation in the mean values was identified. Tukey's test grouped the mean values into four main groups. The highest magnitude, composed by the months of August and July, followed by the group formed by April, December, February and September. The months of May, March, June, November and October were grouped per values of their monthly mean. Lastly, the month of January presented the lowest monthly average, see Figure 5.

When the $\mathrm{AC}$ (in $\mathrm{mBq} \cdot \mathrm{m}^{-3}$ ) were evaluated, statistical differences were also found between the monthly averages, as in the total release. The Tukey test organized the monthly means of AC differently than the total release. In the AC analysis, the months with the highest magnitude of averages were August and February, followed by July and April, and, then November, March, October, May and June. Lastly, the month of January presented a lower average magnitude of released activity concentration, as observed in the total activity released, see Figure 6. 
Figure 5: Analysis of variance between the monthly mean release of radionuclides alpha emitters and Tukey test for grouping the means

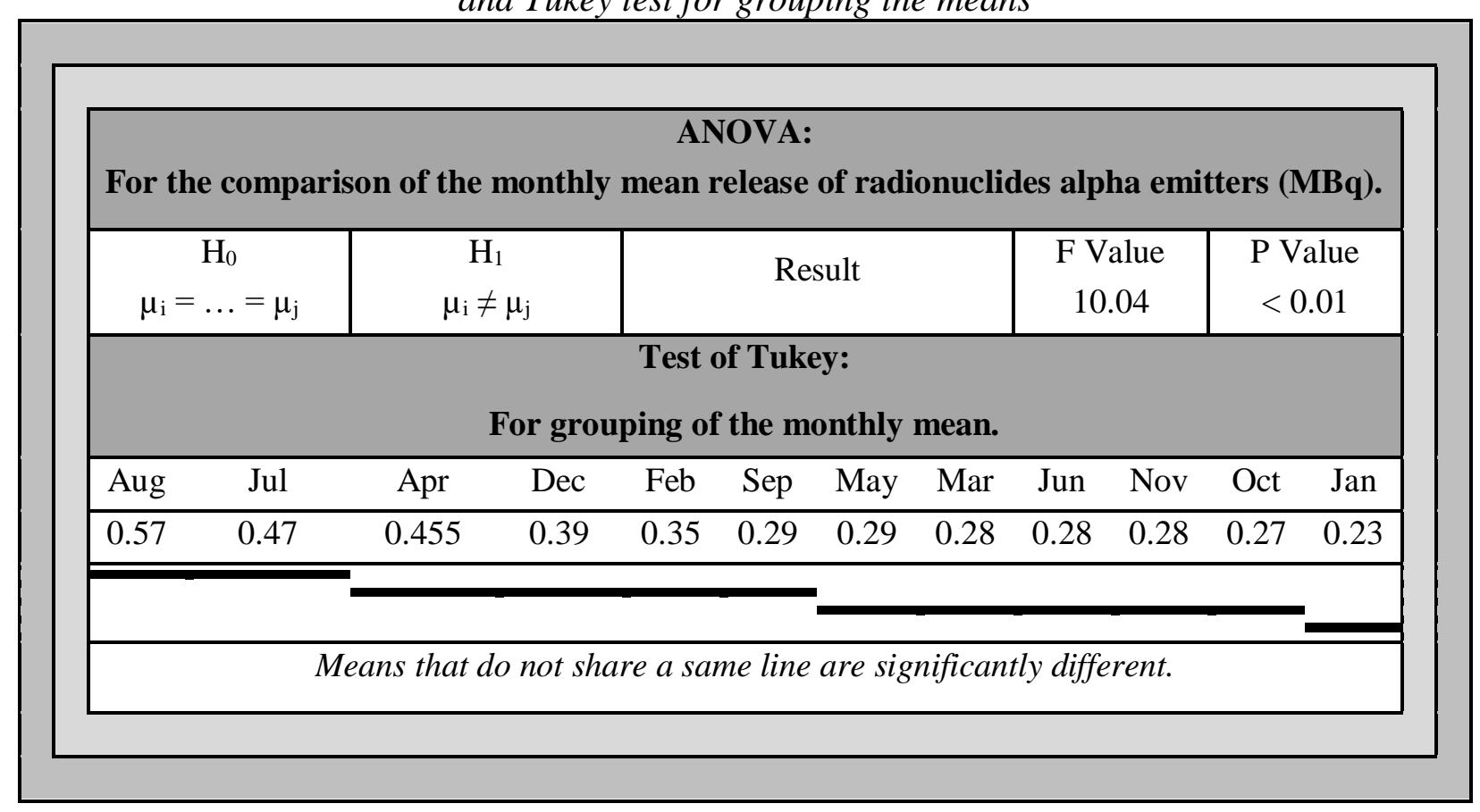

Figure 6: Analysis of variance between the monthly mean release in activity concentration and Tukey test for grouping the means

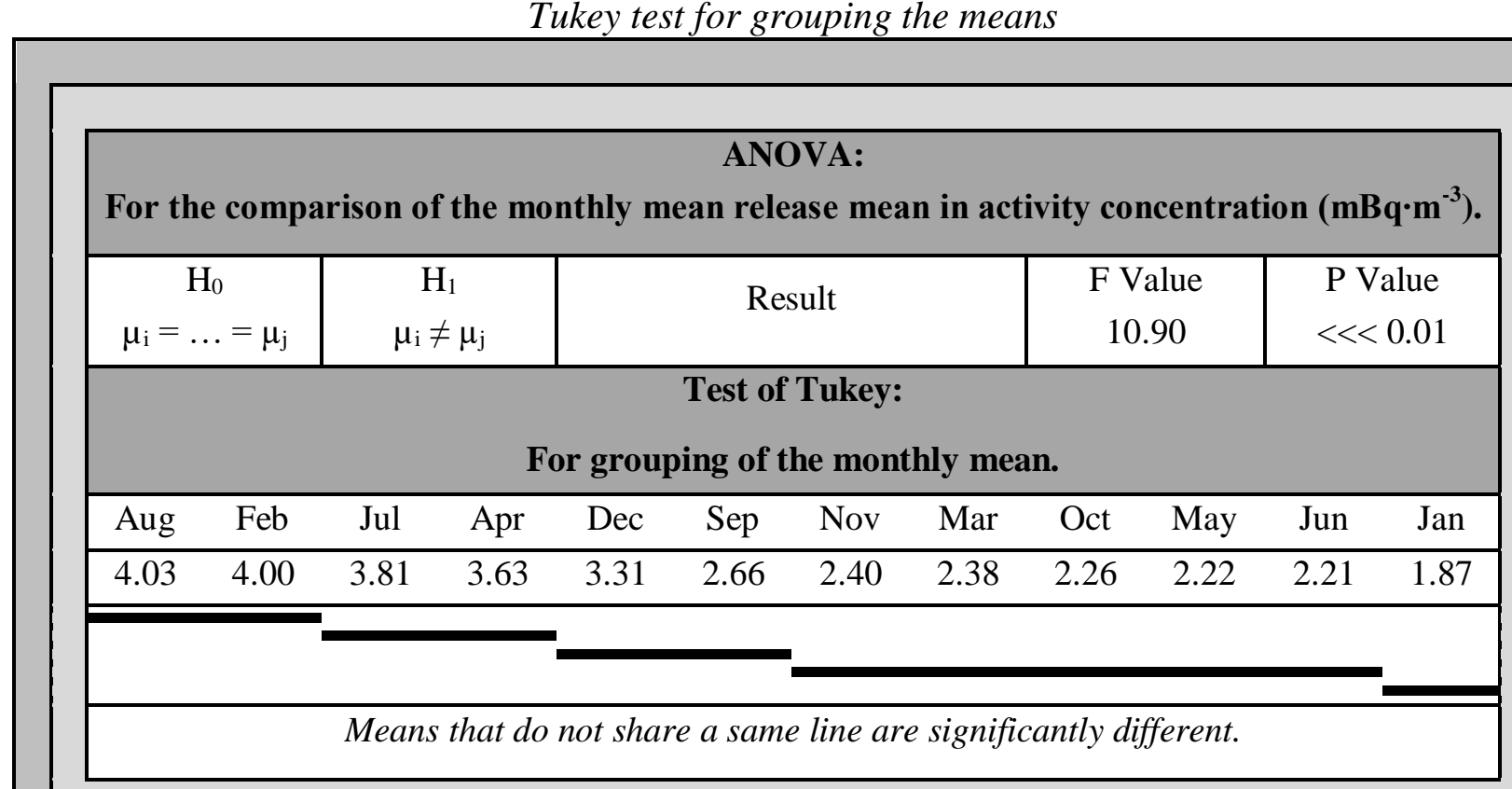




\section{CONCLUSION}

The release of alpha radionuclides emitted by the FCN-II was below half of the limit set in standard, once the total release was $4.14 \mathrm{MBq} \cdot \mathrm{y}^{-1}$ and the legal limit was $12 \mathrm{MBq} \cdot \mathrm{y}^{-1}$.

The total release value is dependent on the activity concentration of alpha emitters in the factory atmosphere, as demonstrated by the high correlation between the variables.

Even with the correlation between the studied variables, the magnitudes of the total release and the concentration of activity have their own characteristics. The arrangement of the monthly averages of the two variables showed different sequences, as described:

\section{For release}

$$
\begin{gathered}
{[(\text { Aug }=\text { Jul })>(\text { Apr }=\text { Dec }=\text { Feb }=\text { Sep })>(\text { May }=\text { Mar }=\text { Jun }=\text { Nov }=\text { Oct })>(\text { Jan })]} \\
\text { For activity concentration } \\
{[(\text { Aug }=\text { Feb })>(\text { Jul =Apr })>(\text { Dec }=\text { Sep })>(\text { Nov }=\text { Mar }=\text { Oct }=\text { May }=\text { Jun })>(\text { Jan })]}
\end{gathered}
$$

Statistical evaluations pointed to an important pattern, which presented the largest magnitudes of the two variables (concentration of activity and release) in August and the smallest ones, in January. Factors such as the industrial production of FCN-II, exhaust air flows and maintenance activities can be used to interpret the behavioral variations of the studied variables and should be the next focus of evaluation.

\section{REFERENCES}

IAEA - INTERNATIONAL ATOMIC ENERGY AGENCY, Environmental and Source Monitoring for Purposes of Radiation Protection, Safety Guide, No. RS-G-1.8, Vienna, Austria, IAEA, 2005. $136 \mathrm{p}$.

—, Stakeholder involvement in nuclear issues: INSAG-20, Vienna, Austria, IAEA, 2006. 16 p.

—, Generic models for use in assessing the impact of discharges of radioactive substances to the environment, SSR-19, Vienna, Austria, IAEA, 2011a. 229 p. 
—, Meteorological and hydrological hazards in site evaluation for nuclear installations, safety guide, no. SSG-18,Vienna, Austria, IAEA, 2011b. 172 p.

—, Radiation Protection and Safety of Radiation Sources: International Basic, Safety Standards, General Safety Requirements Part 3. IAEA, Vienna, Austria: IAEA, 2014a. 441 p.

—, Safety of nuclear fuel cycle facilities, safety standards series, no. NS-R-5, Vienna, Austria, IAEA, 2014b. 123 p.

—, Monitoring and surveillance of radioactive waste disposal facilities, safety standards series, no. SSG-3.1, Vienna, Austria, IAEA, 2014c. 96 p.

—, Site survey and site selection for nuclear installations, Vienna, Austria, IAEA, 2015. 84 p.

—, Safety assessment for facilities and activities, safety standards series, no. GSR part 4, Vienna, Austria, IAEA, 2016a. 63 p.

—, Site evaluation for nuclear installations, safety standards series, no. NS-R-3,Vienna, Austria, IAEA, 2016b. 38 p.

CNEN - Comissão Nacional de Energia Nuclear, Transporte de material radioativo, Rio de Janeiro, Brasil, CNEN, 1988. 88 p.

—, Licenciamento de instalações nucleares, Rio de Janeiro, Brasil, CNEN, 2002. 24 p.

—, Posição regulatória 3.01/008:2011, Programa de monitoração radiológica ambiental, Rio de Janeiro, Brasil, CNEN, 2011. 5 p.

—, Diretrizes básicas de proteção radiológica. Rio de Janeiro, Brasil, CNEN, 2014a. 22 p.

—, Gerência de rejeitos radioativos de baixo e médio níveis de radiação, Rio de Janeiro, Brasil, CNEN, 2014b. 45 p.

ROSNER, B., Fundamentals of biostatistic. $1^{\text {st }}$ ed. Stanford: Duxbury Thonson Learning, 2000.

SCHORK, M. A. and REMINGTON, R. D., $2^{\text {nd }}$ ed. Statistic with applications to the biological and Health science. Prentice: Upper Saddle River, 2000.

FERREIRA, D. F., Estatística multivariada. $1^{\text {st }}$ ed. Lavras: UFLA, 2008. 